\title{
Study on the Interaction of Collinear Cracks and Wing Cracks and Cracking Behavior of Rock under Uniaxial Compression
}

\author{
Chaolin Wang, ${ }^{1,2}$ Yu Zhao $\mathbb{D D}^{1,3}$ Yanlin Zhao ${ }^{10},{ }^{4}$ and Wen Wan ${ }^{4}$ \\ ${ }^{1}$ School of Civil Engineering, Chongqing University, Chongqing 400045, China \\ ${ }^{2}$ Key Laboratory of Geotechnical Engineering Stability Control and Health Monitoring of Hunan Province, \\ Hunan University of Science and Technology, Xiangtan, Hunan 411201, China \\ ${ }^{3}$ Key Laboratory of New Technology for Construction of Cities in Mountain Area, Ministry of Education, \\ Chongqing University, Chongqing 400030, China \\ ${ }^{4}$ School of Resource, Environment and Safety Engineering, Hunan University of Science and Technology, Xiangtan, \\ Hunan 411201, China \\ Correspondence should be addressed to Yu Zhao; zytyut1@126.com
}

Received 3 October 2017; Accepted 15 March 2018; Published 3 April 2018

Academic Editor: Robert Černý

Copyright (c) 2018 Chaolin Wang et al. This is an open access article distributed under the Creative Commons Attribution License, which permits unrestricted use, distribution, and reproduction in any medium, provided the original work is properly cited.

\begin{abstract}
This paper investigates the crack interaction, initiation, and propagation rules of rock-like materials containing two collinear cracks. Based on the Kachanov method, the formulations for stress intensity factors (SIFs) of two collinear cracks and two winged cracks are derived, respectively. The influences of bridge ligament and crack length on the crack interaction are analyzed theoretically. The results show that the propagation of a long crack is independent of crack interaction when $d \geq a_{2}$ and the same rule applies for a short crack when $d \geq a_{1}$. With the growth of wing cracks, the SIF of wings first remarkably decreases and then it tends toward a steady value. Subsequently, the propagation of collinear cracks and cracking processes under uniaxial compression are analyzed experimentally and numerically. Both the experimental results and simulation results demonstrate that shear cracks tend to initiate and propagate at higher inclination angle. The crack coalescence is affected by the inclination angle of bridge ligament. For increasing the inclination angle, the crack coalescence varies from wing crack failure to shear crack coalescence. As bridge ligament increases, the crack coalescence varies from shear crack coalescence to shear-wing crack coalescence and then to wing crack failure.
\end{abstract}

\section{Introduction}

Rock and rock-like materials usually contain a number of cracks, which affect the physical properties and influence the failure patterns of the rock material. Cracks will interact with each other, and the cracking behavior of rock materials critically depends on the crack interaction [1]. In order to improve the understanding of fracture mechanism of brittle materials with multiple cracks, abundant theoretical and experimental studies have been conducted on rock materials containing two cracks [2-4].

The effect of the crack interaction on the failure behavior of material has received significant attentions in recent years and various methods have been developed for the analyses, including singular integral equation method [5-7], Kachanov method [8,9], and modified Kachanov method [1, 10]. Lekesiz et al. [11] investigated the effect of crack interactions on the SIF for a periodic array of coplanar penny-shaped cracks using Kachanov's approximate method. Kastratović et al. [12] presented an approximate procedure for stress intensity factors determination in case of multiple cracks and was verified by comparison with the simulation results. Jogdand and Murthy [13] suggested a simple and efficient method for simultaneous estimation of the mixed-mode SIF and $\mathrm{T}$-stresses using finite element computations. Although considerable progresses have been made for stress intensity factors determination of multiple cracks, to accurately describe the effect of the crack interaction on the failure 
behavior of material is an issue that is not completely resolved, especially for unequal collinear cracks and winged cracks. Usually, for curvilinear winged cracks the crack-crack interaction problem is solved numerically [14]. Although a lot of wing crack models were proposed to determine the SIF [15-18], few of these models took consideration of the interaction of wing cracks.

The interaction of cracks can significantly accelerate the speed of rock failure. The previous work provides a good understanding of the effect of interaction on mechanical properties. The experimental studies on rock-like materials containing cracks indicate that the geometry of the preexisting cracks, such as crack inclination angle, bridge ligament angle, and crack aperture have a strong influence on strength $[2,4,19]$, coalescence behavior $[3,20-22]$, and fatigue life of the structural component [23, 24]. To obtain a more comprehensive understanding of the mechanics, further experimental and numerical studies should be performed. The present paper is restricted to models containing only two collinear cracks.

In this paper, the SIF of two unequal collinear cracks is first derived using the Kachanov method, and then the formulation of determining the SIF of two winged interacting cracks is developed. Subsequently, crack propagation and coalescence are investigated experimentally and numerically. At last, the influences of inclination angle and bridge ligament on cracking are explored.

\section{Interaction of Unequal Collinear Cracks}

2.1. Kachanov Method. Let us consider an infinite plate containing two cracks and lying at the angle $\beta_{i}(i=1,2)$ to the horizontal plane. The coordinate figure is described in Figure 1 . One can resolve the traction $\mathbf{p}_{i}^{\infty}$ loaded on crack faces into two components, $\sigma_{n i}^{\infty}$ and $\sigma_{t i}^{\infty}$. For open cracks, the traction $\mathbf{p}_{i}^{\infty}$ is

$$
\mathbf{p}_{i}^{\infty}=\left\{\begin{array}{c}
-\sigma_{n i}^{\infty} \\
-\sigma_{t i}^{\infty}
\end{array}\right\}=-\left\{\begin{array}{c}
\frac{\sigma^{\infty}\left(1+\cos 2 \beta_{i}\right)}{2} \\
\frac{\sigma^{\infty} \sin 2 \beta_{i}}{2}
\end{array}\right\} \quad(i=1,2) .
$$

For close cracks, the traction $\mathbf{p}_{i}^{\infty}$ is

$$
\begin{aligned}
\mathbf{p}_{i}^{\infty} & =\left\{\begin{array}{c}
-\sigma_{n i}^{\infty} \\
-\sigma_{t i}^{\infty}
\end{array}\right\} \\
& =-\left\{\begin{array}{c}
\sigma^{\infty}\left(1+\cos 2 \beta_{i}\right) \\
\frac{\sigma^{\infty} \sin 2 \beta_{i}}{2}-\mu \sigma^{\infty}\left(1+\cos 2 \beta_{i}\right)
\end{array}\right\} \quad(i=1,2),
\end{aligned}
$$

where $\mu$ is the coefficient of friction.

Based on the superposition principle, the problem can be replaced by a superposition of 2 subproblems and each contains one crack but is loaded by pseudotractions $\mathbf{p}_{i}\left(\xi_{i}\right)$ [1]. Kachanov decomposed the pseudotractions into two components: average component and varying component,

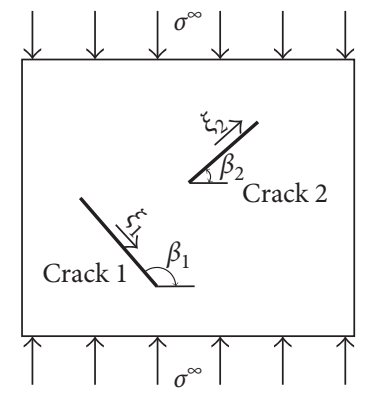

Figure 1: An infinite plate containing two cracks under uniaxial compression.

and the resultant force of the varying component is zero [9]. Hence, $\mathbf{p}_{i}\left(\xi_{i}\right)$ can be expressed as

$$
\mathbf{p}_{i}\left(\xi_{i}\right)=\left\{\begin{array}{c}
\sigma_{n i}\left(\xi_{i}\right) \\
\sigma_{t i}\left(\xi_{i}\right)
\end{array}\right\}=\mathbf{p}_{i}^{\infty}+\Delta \mathbf{p}_{i j}\left(\xi_{i}\right) \quad(i=1,2),
$$

where the unknown crack interaction stresses $\Delta \mathbf{p}_{i j}\left(\xi_{i}\right)$ are the traction on the $i$ th crack due to interaction with the $j$ th crack.

$$
\Delta \mathbf{p}_{i j}\left(\xi_{i}\right)=\left\{\begin{array}{c}
\Delta \sigma_{n i}\left(\xi_{i}\right) \\
\Delta \sigma_{t i}\left(\xi_{i}\right)
\end{array}\right\}=\left[\begin{array}{cc}
f_{i j}^{n n} & f_{i j}^{n t} \\
f_{i j}^{t n} & f_{i j}^{t t}
\end{array}\right]\left\{\begin{array}{c}
\left\langle\sigma_{n j}\left(\xi_{i}\right)\right\rangle \\
\left\langle\sigma_{t j}\left(\xi_{i}\right)\right\rangle
\end{array}\right\},
$$

where $\Delta \sigma_{n i}\left(\xi_{i}\right)$ and $\Delta \sigma_{t i}\left(\xi_{i}\right)$ are normal and shear stresses on the $i$ th crack induced by the traction of the $j$ th crack; $\left\langle\sigma_{n j}\left(\xi_{i}\right)\right\rangle$ and $\left\langle\sigma_{t j}\left(\xi_{i}\right)\right\rangle$ denote the average normal and shear stresses on the $i$ th crack; $f_{i j}^{n n}, f_{i j}^{n t}, f_{i j}^{t n}$, and $f_{i j}^{t t}$ are interaction coefficients, and their explicit forms are given in [8].

Taking the averages for (3), we obtain

$$
\begin{aligned}
\left\langle\mathbf{p}_{i}\left(\xi_{i}\right)\right\rangle & =\left\{\begin{array}{c}
\left\langle\sigma_{n j}\left(\xi_{i}\right)\right\rangle \\
\left\langle\sigma_{t j}\left(\xi_{i}\right)\right\rangle
\end{array}\right\} \\
& =\left\{\begin{array}{c}
-\sigma_{n i}^{\infty} \\
-\sigma_{t i}^{\infty}
\end{array}\right\}+\left[\begin{array}{cc}
\Lambda_{i j}^{n n} & \Lambda_{i j}^{n t} \\
\Lambda_{i j}^{t n} & \Lambda_{i j}^{t t}
\end{array}\right]\left\{\begin{array}{c}
\left\langle\sigma_{n j}\left(\xi_{i}\right)\right\rangle \\
\left\langle\sigma_{t j}\left(\xi_{i}\right)\right\rangle
\end{array}\right\},
\end{aligned}
$$

where $\Lambda_{i j}^{n n}, \Lambda_{i j}^{n t}, \Lambda_{i j}^{t n}$, and $\Lambda_{i j}^{t t}$ are transmission factors due to unit intensity tractions. On solving (5), we have the average tractions $\left\langle\sigma_{n j}\left(\xi_{i}\right)\right\rangle$ and $\left\langle\sigma_{t j}\left(\xi_{i}\right)\right\rangle$. Therefore, the pseudotractions can be determined by combining (3) and (4). Once the pseudotractions are known, the stress intensity factor (SIF) in this phase can be determined according to [14].

$$
\left.\begin{array}{l}
K_{\mathrm{I}}\left( \pm a_{i}\right) \\
K_{\mathrm{II}}\left( \pm a_{i}\right)
\end{array}\right\}=-\frac{1}{\sqrt{\pi a_{i}}} \int_{-a_{i}}^{a_{i}} \sqrt{\frac{a_{i} \pm \xi_{i}}{a_{i} \mp \xi_{i}}}\left\{\begin{array}{l}
\sigma_{n i}\left(\xi_{i}\right) \\
\sigma_{t i}\left(\xi_{i}\right)
\end{array}\right\} d \xi_{i} .
$$

\subsection{Example of the Kachanov Method: Unequal Collinear} Cracks. Figure 2 shows two unequal collinear cracks, lying at the angle $\beta$ to the horizontal plane. For this configuration, values of $f_{i j}^{n t}$ and $f_{i j}^{t n}$ for collinear cracks are zero, and the rest of the coefficients are computed as 


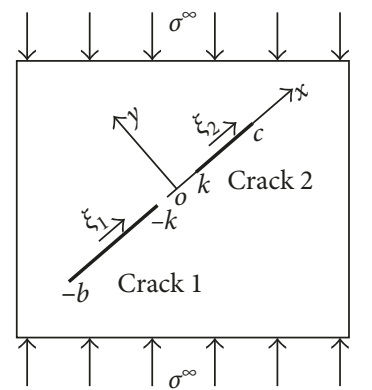

FIGURE 2: An infinite plate containing two unequal collinear cracks.

$$
\begin{aligned}
& f_{12}^{n n}=f_{12}^{t t}=\frac{\xi_{1}+(c+b+2 k) / 2}{\sqrt{\left(\xi_{1}+(c+b+2 k)\right)^{2}-((c-k) / 2)^{2}}}-1, \\
& f_{21}^{n n}=f_{21}^{t t}=-\frac{\xi_{1}-(c+b+2 k) / 2}{\sqrt{\left(\xi_{1}-(c+b+2 k)\right)^{2}-((c-k) / 2)^{2}}}-1 .
\end{aligned}
$$

The transmission factors can be computed by

$$
\begin{aligned}
\Lambda_{12}^{n n} & =\Lambda_{12}^{t t}=\frac{1}{c-k} \int_{(k-c / 2)}^{(c-k / 2)} f_{12}^{n n} d \xi_{2} \\
& =\frac{\sqrt{(c+b)(c+k)}-\sqrt{2 k(c+k)}}{c-k}-1, \\
\Lambda_{21}^{n n} & =\Lambda_{21}^{t t}=\frac{1}{b-k} \int_{(k-b / 2)}^{(b-k / 2)} f_{12}^{n n} d \xi_{1} \\
& =\frac{\sqrt{(c+b)(b+k)}-\sqrt{2 k(c+k)}}{b-k}-1 .
\end{aligned}
$$

Substituting (8) and (9) in (5), we can obtain the average tractions and finally get the pseudotractions. Note that for sliding close cracks, $\sigma_{n i}\left(\xi_{i}\right)$ is equal to zero. Combination with (6), the explicit forms of inner tip SIFs in unequal collinear cracks subject to compression loads are given as

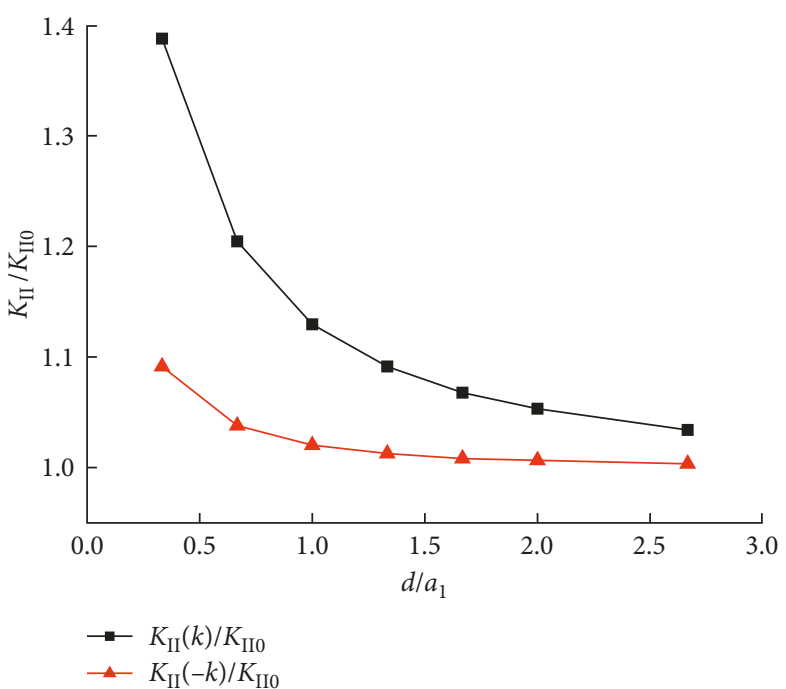

FIGURE 3: Relation of the normalized SIF and $d / a_{1}$ for two unequal collinear cracks $\left(a_{1}=2 a_{2}, \beta=45^{\circ}\right)$.

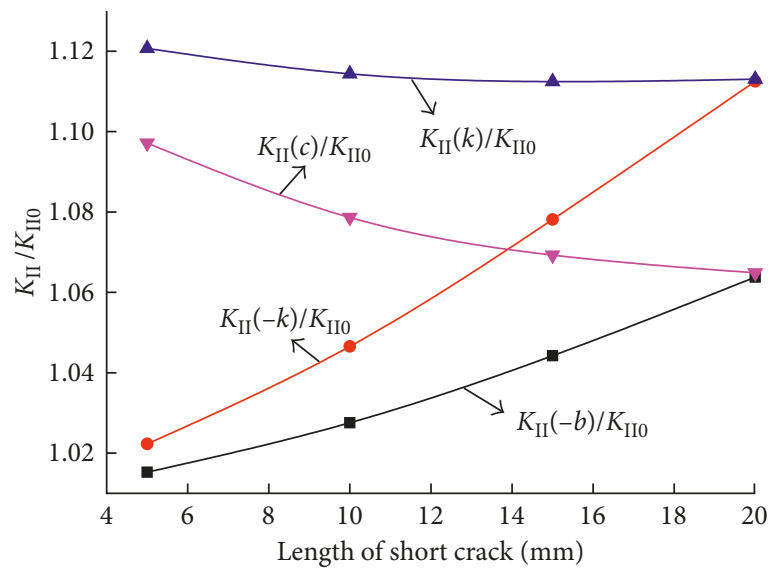

FIGURE 4: Relation of the normalized SIF and crack length for two unequal collinear cracks $\left(a_{1}=d=10 \mathrm{~mm}, \beta=45^{\circ}\right)$.

$$
\begin{aligned}
& K_{\mathrm{II}}(-k)=\frac{\sigma^{\infty} \sin 2 \beta-\mu \sigma^{\infty}(1+\cos 2 \beta)}{2 \sqrt{\pi a_{1}}} \int_{-a_{1}}^{a_{1}} \sqrt{\frac{a_{1}+\xi_{1}}{a_{1}-\xi_{1}}}\left[1+\frac{1+\Lambda_{12}^{n n}}{1-\Lambda_{12}^{n n} \Lambda_{21}^{n n}}\left(-\frac{\xi_{1}-(c+b+2 k) / 2}{\sqrt{\left(\xi_{1}-(c+b+2 k) / 2\right)^{2}}-((c-k) / 2)^{2}}-1\right)\right] d \xi_{1}, \\
& K_{\mathrm{II}}(k)=\frac{\sigma^{\infty} \sin 2 \beta-\mu \sigma^{\infty}(1+\cos 2 \beta)}{2 \sqrt{\pi a_{2}}} \int_{-a_{2}}^{a_{2}} \sqrt{\frac{a_{2}-\xi_{2}}{a_{2}+\xi_{2}}}\left[1+\frac{1+\Lambda_{21}^{n n}}{1-\Lambda_{12}^{n n} \Lambda_{21}^{n n}}\left(\frac{\xi_{2}+(c+b+2 k) / 2}{\sqrt{\left(\xi_{2}+(c+b+2 k) / 2\right)^{2}}-((c-k) / 2)^{2}}-1\right)\right] d \xi_{2} .
\end{aligned}
$$

The normalized stress intensity factor $\left(K / K_{0}\right.$, where $K_{0}$ refers to a single crack solution under the given load) is shown in Figure 3, using (10) and (11). Obviously, the mutual effect of cracks is sensitive to the separation distance (hereafter denoted "bridge ligament") of two cracks. With bridge ligament increases, the SIF of crack tips decreases, indicating the drop of mutual effect. The mutal effect is assumed to be negligible for $K / K_{0}<1.05$ [25]. It is found 


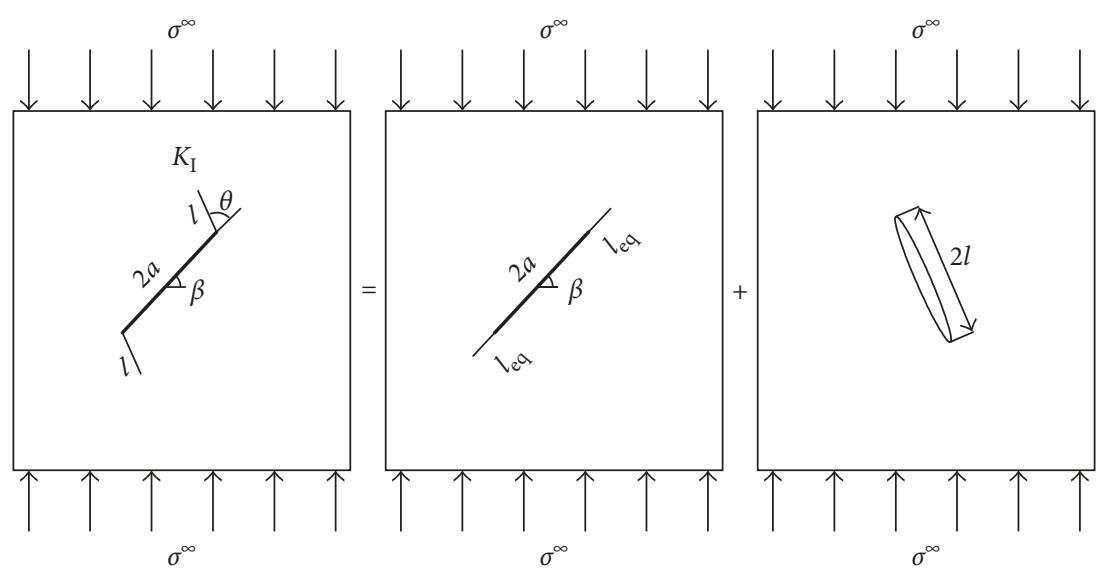

FIgURE 5: Computation of the SIF at the wing crack tip by using the superposition technique [17].

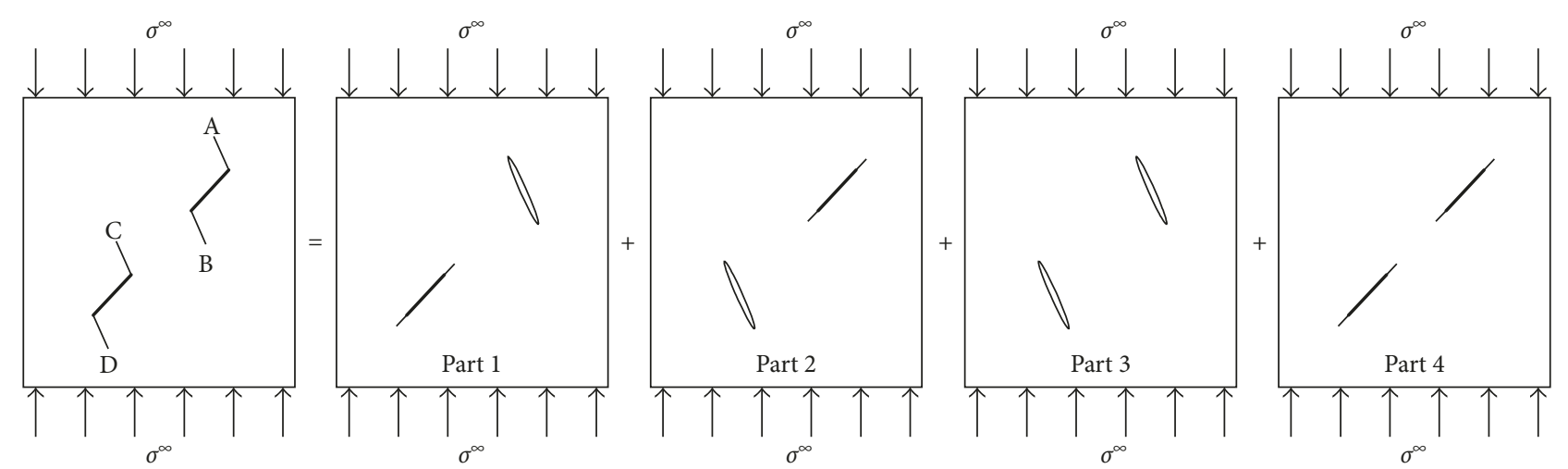

FIgURE 6: Computation of the SIF for the interacted wing crack tip by using the superposition technique.

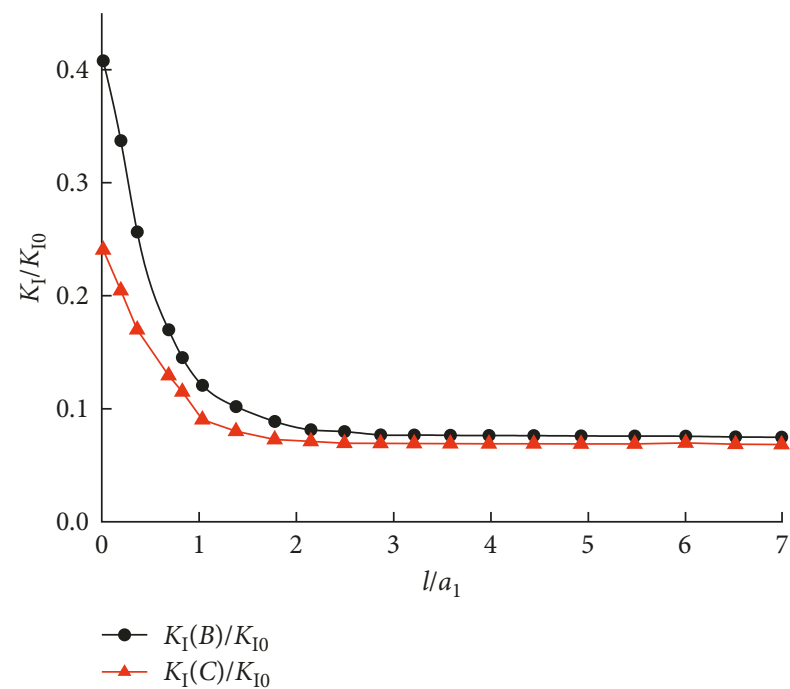

FIGURE 7: Relation of the normalized SIF and wing crack length $\left(a_{1}=a_{2}, \beta=45^{\circ}, \theta=70.5^{\circ}\right)$.

that the propagation of a long crack is independent of crack interaction when $d \geq a_{2}$, and the same rule applies for a short crack when $d \geq a_{1}$.

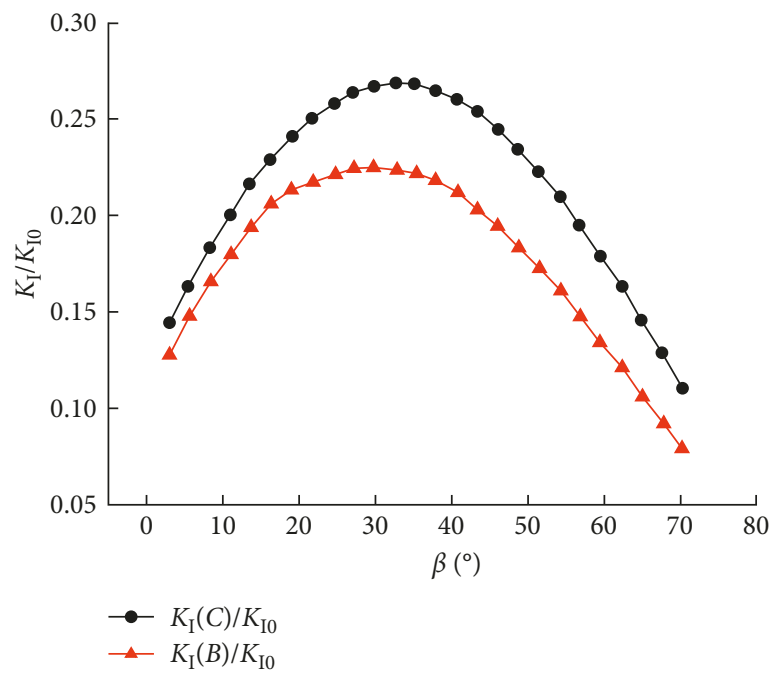

FIGURE 8: Relation of the normalized SIF and preexisting crack inclination angle $\left(a_{1}=a_{2}, l / a_{1}=0.5, \theta=70.5^{\circ}\right)$.

Figure 4 shows the curve of the normalized SIF versus the crack length. The figure clearly indicates that the SIF of four tips are larger than the value of a single crack due to the 
TABLE 1: Material properties of the specimens.

\begin{tabular}{|c|c|c|c|c|c|c|c|}
\hline Type & $\begin{array}{c}\text { Crack inclination } \\
\text { angle }\left({ }^{\circ}\right)\end{array}$ & $\begin{array}{l}\text { Crack length } \\
(\mathrm{mm})\end{array}$ & $\begin{array}{l}\text { Bridge ligament } \\
(\mathrm{mm})\end{array}$ & $\begin{array}{l}\text { UCS } \\
(\mathrm{MPa})\end{array}$ & $\begin{array}{l}\text { Poisson's } \\
\text { ratio }\end{array}$ & $\begin{array}{l}\text { Density } \\
\left(\mathrm{g} / \mathrm{cm}^{3}\right)\end{array}$ & $\begin{array}{c}\text { Elastic modulus } \\
(\mathrm{GPa})\end{array}$ \\
\hline \multirow{3}{*}{ Specimens with collinear cracks } & $25^{\circ}$ & 20 & 40 & 15.2 & \multirow{4}{*}{0.23} & \multirow{4}{*}{2.11} & \multirow{4}{*}{2.45} \\
\hline & $45^{\circ}$ & 20 & 40 & 19.8 & & & \\
\hline & $75^{\circ}$ & 20 & 40 & 20.7 & & & \\
\hline Intact specimen & - & - & - & 24.8 & & & \\
\hline
\end{tabular}

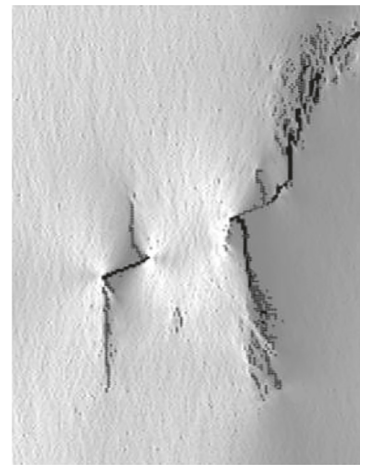

(a)

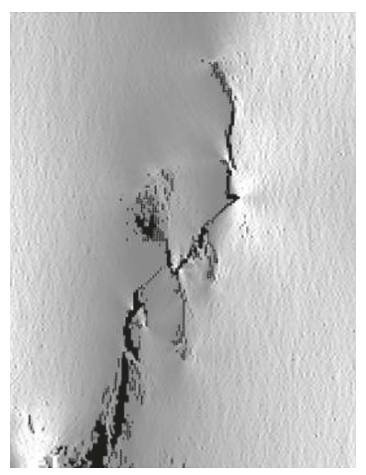

(c)

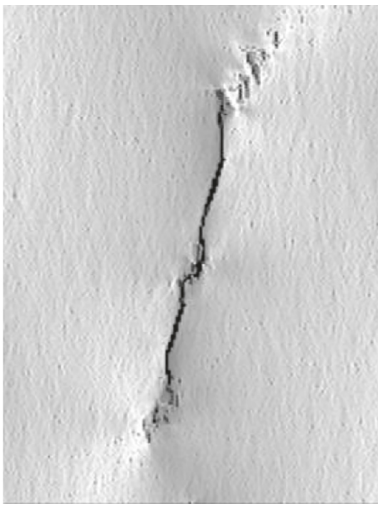

(e)
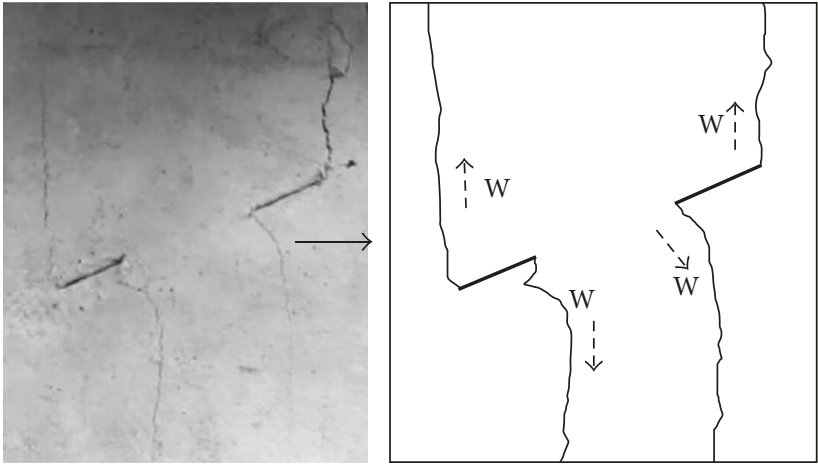

(b)
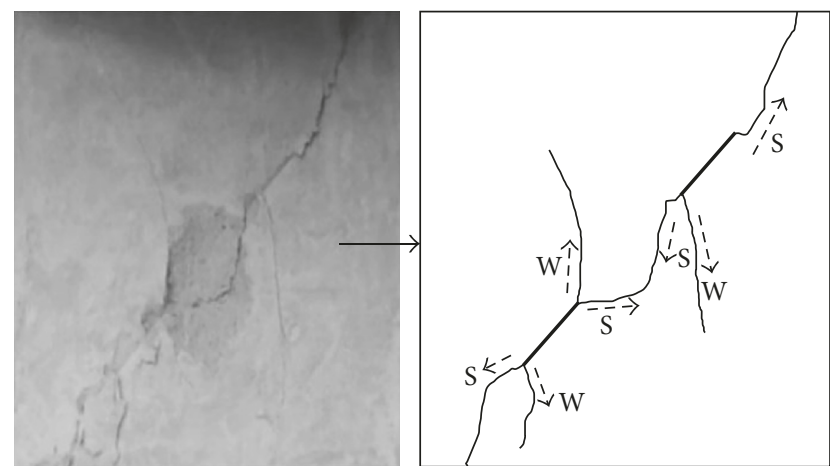

(d)
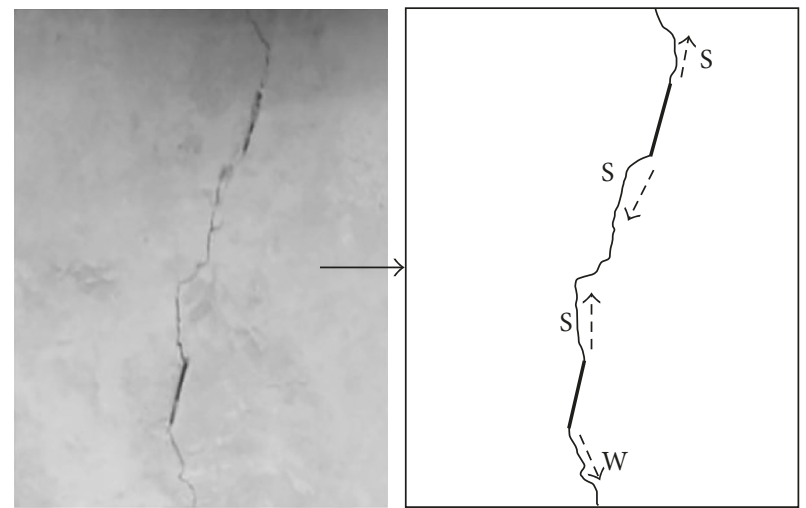

(f)

Figure 9: Comparison of numerical results and experimental results for two equal collinear cracks with varied inclination angles $\left(a_{1}=a_{2}=20 \mathrm{~mm}, d=40 \mathrm{~mm} ; \mathrm{W}=\right.$ wing crack; $\mathrm{S}=$ shear crack). (a) Simulation results for $\beta=25^{\circ}$. (b) Experimental results for $\beta=25^{\circ}$. (c) Simulation results for $\beta=45^{\circ}$. (d) Experimental results for $\beta=45^{\circ}$. (f) Experimental results for $\beta=75^{\circ}$. (f) Experimental results for $\beta=75^{\circ}$.

crack-crack interaction, and the effect of crack interaction on outer tips is smaller than that on inner tips. Note that the SIFs of outer tips and inner tips are equal to each other for $a_{1}=a_{2}$. As the length of crack 2 (hereafter denoted "short crack") decreases, the SIF of inner and outer tips at crack 1 (hereafter denoted "long crack") decreases, but increases for 


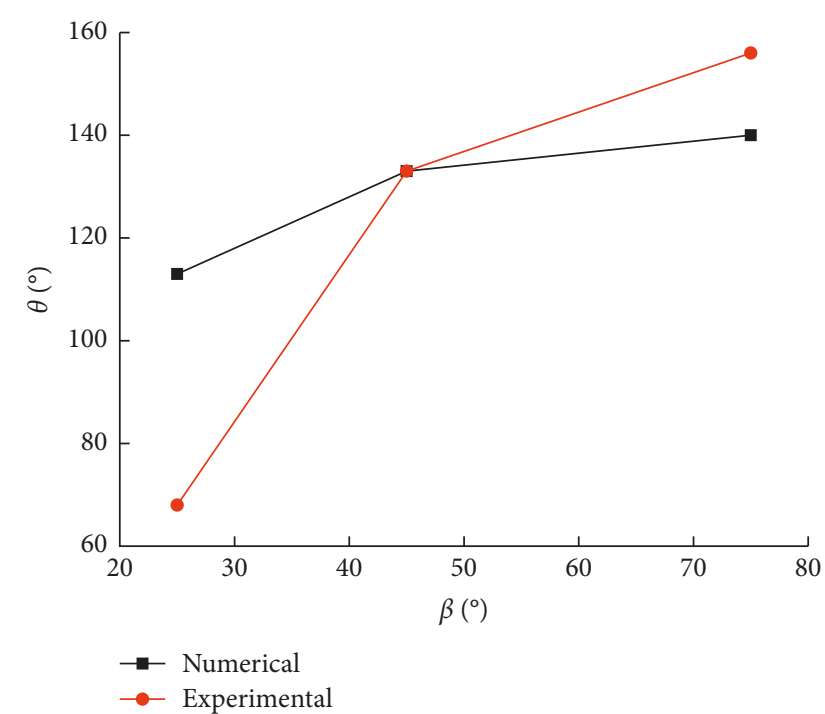

FIgURE 10: Relation of the inclination angle and the initiation angle.

the short crack. This demonstrates that the decrease in short crack length weakens the influence of crack interaction on the long crack. When the length of the short crack is less than bridge ligament, $K_{\mathrm{II}} / K_{\mathrm{II} 0}<1.05$, interaction between cracks becomes dispensable.

\section{Determination of SIF for Two Interacting Wing Cracks}

Consider a problem of two collinear cracks with equal length (i.e., $b=c$, shown in Figure 2) in a plate subjected to compression loads. Previous studies illustrated that the initial cracking was in accordance with mode-I under compression-shear stresses $[3,26]$. The crack slides when shear stress exceeds the fractional resistance. Consequently, stress-induced wing cracks generate (Figure 5(a)). The evolution of the SIF at the tip of the wing crack has been studied quantitatively by a number of researchers. Although most of them proposed their own winged crack models [15-18], few of these models took consideration of the interaction of wing cracks. In this section, we try to develop a computation of the SIF at the tip of interacted wing cracks.

In order to calculate an approximate $K_{I}$ value, Baud replaced the winged crack with two components [17]: (1) an equivalent single straight crack of length $2\left(a+l_{\mathrm{eq}}\right) ;(2)$ a straight wing crack of length $2 l$ (Figure 5). Using this method, we decompose the interacted winged cracks into four parts (shown in Figure 6). Therefore, the $\operatorname{SIF} K_{\mathrm{I}}(A)$ at the outer wing tip of the crack can be expressed as

$$
K_{\mathrm{I}}(A)=K_{\mathrm{I}}^{(1)}(A)+K_{\mathrm{I}}^{(2)}(A)+K_{\mathrm{I}}^{(3)}(A)+K_{\mathrm{I}}^{(4)}(A),
$$

where $K_{\mathrm{I}}^{(i)}(A)$ is the SIF at the outer wing tip of the upper crack in the $i$ th part $(i=1,2,3,4)$, which can be calculated using the Kachanov method discussed in Section 2.1. Note that for sliding close crack $K_{\mathrm{I}}^{(i)}(A)=0$ (i.e., $K_{\mathrm{I}}^{(2)}(A)=0$,
$\left.K_{\mathrm{I}}^{(4)}(A)=0\right)$. Similarly, $K_{\mathrm{I}}(B), K_{\mathrm{I}}(C)$ and $K_{\mathrm{I}}(D)$ can also be obtained.

Figure 7 presents the relationship between the normalized SIF of crack tip and the length of wing crack $l$ obtained from (12). As the length of the wing crack increases, the SIF of four tips first remarkably decreases when $l / a_{1}<2$ and then it tends toward a steady value for $l / a_{1}>2$. Figure 8 presents the relationship between the normalized SIF of crack tips and the crack inclination angle $\beta$. It illustrates that the SIF first experiences a rush climb and then suffers a rapid drop with the increase of $\beta$. The mutual effect on the SIF of inner tips is stronger than that of outer tips, but this effect diminishes as the wing crack grows.

\section{Experimental and Numerical Tests for Crack Propagation}

4.1. Experimental Tests. In this section, crack propagation processes under uniaxial compression are analyzed experimentally and numerically. The experimental material is a mixture of ordinary Portland cement, sand, and water at a ratio of $26: 25: 10$ by weight. The specimens, with dimensions $200 \mathrm{~mm}$ high, $150 \mathrm{~mm}$ wide, and around $30 \mathrm{~mm}$ thick, contain a pair of collinear cracks. The crack geometry is characterized by crack length, bridge ligament, and crack inclination angle. Specifically, in this test, both the crack lengths are set to $20 \mathrm{~mm}$, the bridge ligament is set to two times of crack length, and the crack inclination angles are set to $25^{\circ}, 45^{\circ}$, and $75^{\circ}$, respectively. A digital camera is employed to capture the instants of crack initiation during the whole loading process. The material properties of the specimens are given in Table 1.

The test results show an increase of uniaxial compressive strength (UCS) with the crack inclination angle (Table 1). Such trend is in qualitative agreement with the experimental results in $[2,21]$. Figure 9 shows the experimental results of collinear crack propagation. It reveals that the crack propagates from the tip of the crack, and the initiation of the shear crack depends on the inclination of the preexisting crack. For shallowly inclined cracks (small inclination angle), only wing cracks are observed (Figure 9(a)). According to (1) and (2), a smaller inclination angle leads to a lower shear stress on the crack. As a consequence, the shear stress is not sufficient enough to trigger shear cracks, but induces wing cracks and drives their propagation.

4.2. Numerical Analysis. With reference to the experimental observation of crack initiation, numerical analysis was carried out to simulate the cracking processes by means of the two-dimensional finite element code RFPA. The element's random strength and elastic modulus are spatially distributed according to a Weibull parameter $m$ [27], which is set to 5 in this paper. A state of plane strain is assumed, and a Coulomb criterion envelope with a tensile cutoff is adopted so that the elements may fail in a shear or tensile mode [28]. The numerical tests are conducted under constant displacement rate $(0.002 \mathrm{~mm} / \mathrm{step})$ in the vertical direction to produce a compression loading. To mimic the laboratory 

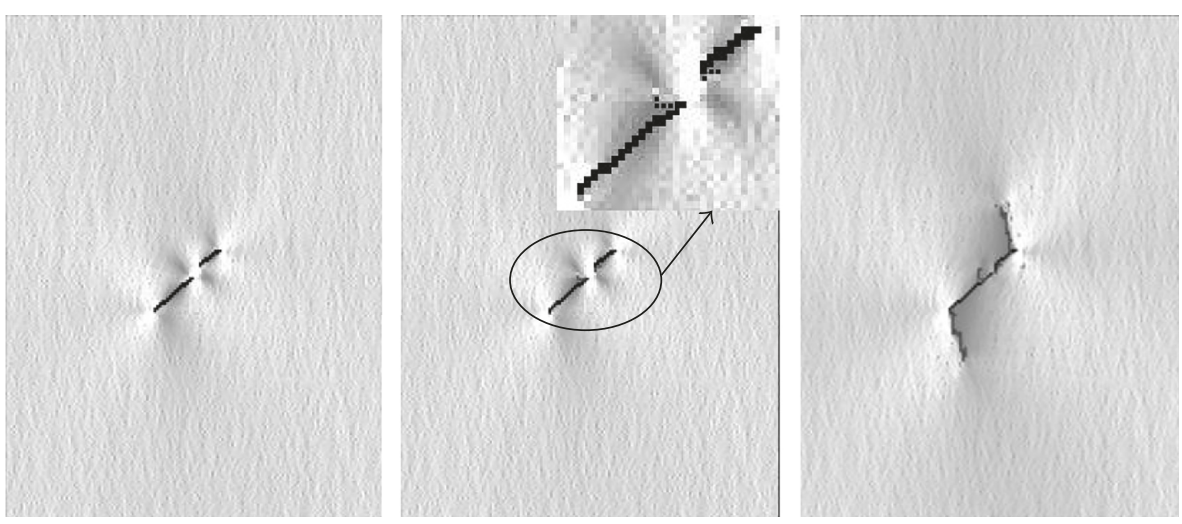

(a)
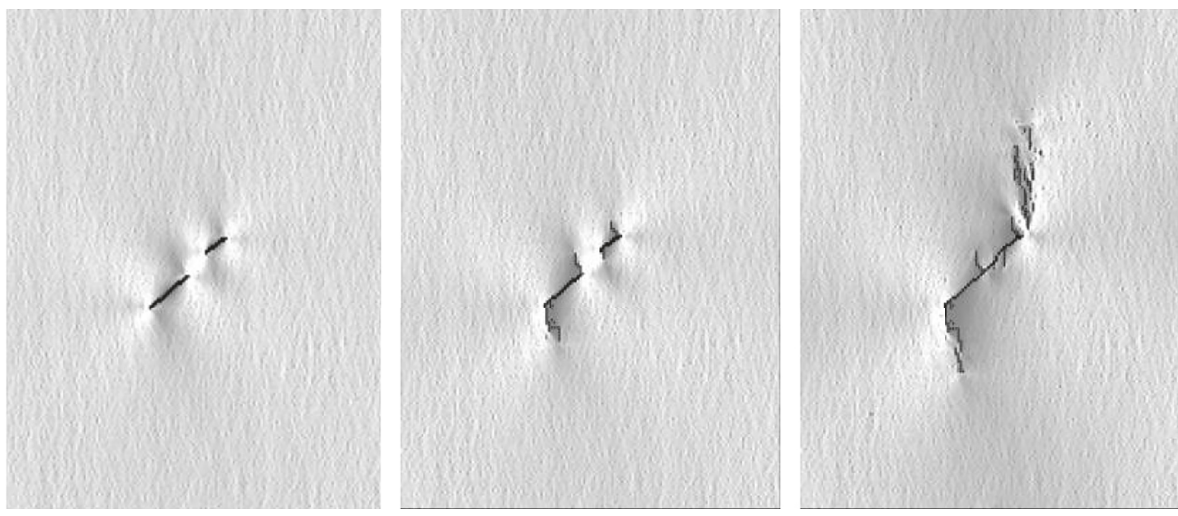

(b)
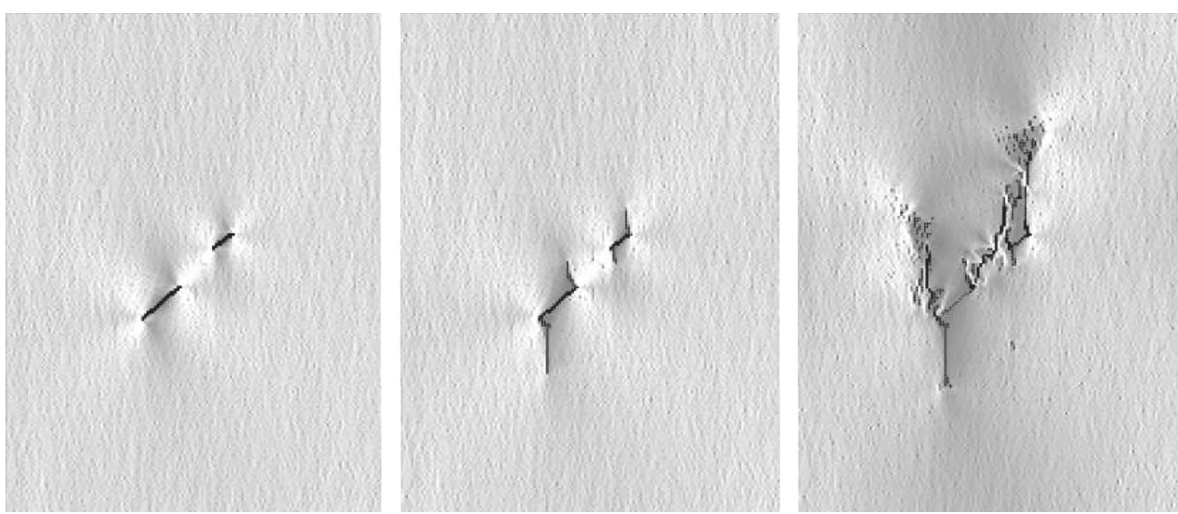

(c)
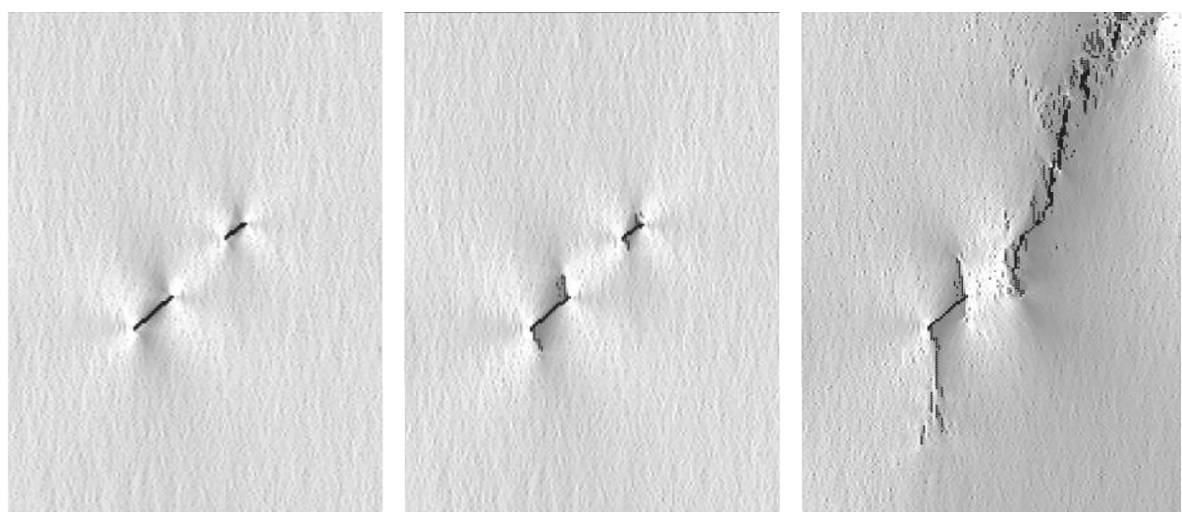

(d)

Figure 11: Continued. 

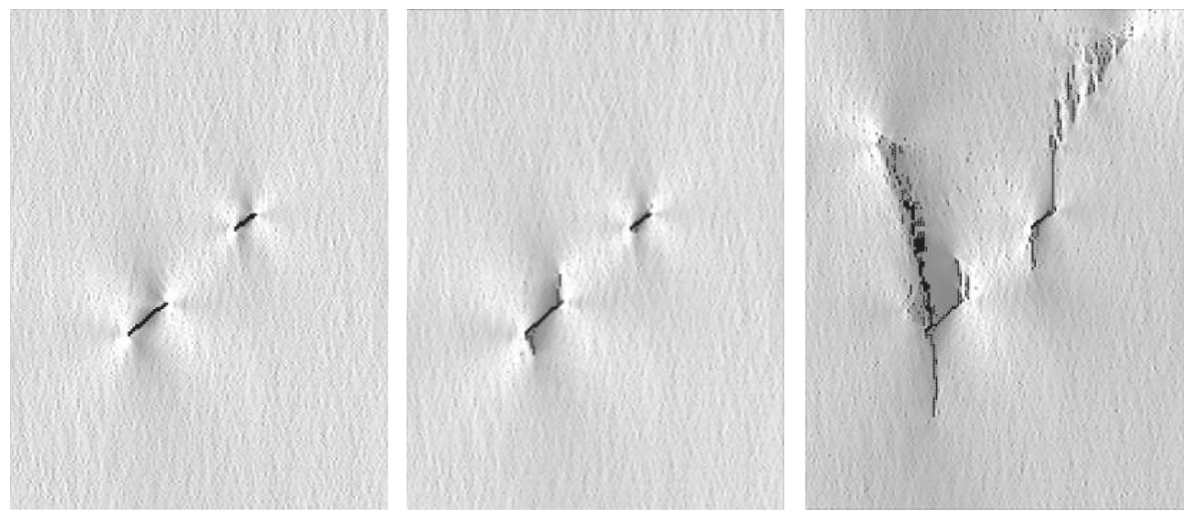

(e)

Figure 11: Simulation results of two unequal collinear cracks with varied bridge ligament $\left(a_{1}=2 a_{2}=20 \mathrm{~mm}, \beta=45^{\circ}\right)$. (a) $d=5 \mathrm{~mm}$, shear crack coalescence. (b) $d=10 \mathrm{~mm}$, wing crack coalescence. (c) $d=20 \mathrm{~mm}$, shear-wing crack coalescence. (d) $c=30 \mathrm{~mm}$, wing crack failure. (e) $d=40 \mathrm{~mm}$, wing crack failure.

configuration, the model size and crack geometric parameters are set consistent with experimental condition. The mesh size is set as $150 \times 200=30,000$, and the values of Young's modulus, Poisson's ratio, density, and USC are listed in Table 1 . The simulation proceeds in two parts: failure simulation of equal collinear cracks $\left(a_{1}=a_{2}=20 \mathrm{~mm}\right)$ to compare with experimental date and failure simulation of unequal collinear cracks $\left(a_{1}=2 a_{2}=20 \mathrm{~mm}\right)$ to validate the theory proposed in Section 2.2.

Figure 9 illustrates the damage evolution and failure processes of equal collinear cracks with varied inclination angles from $25^{\circ}$ to $75^{\circ}$. Comparing the numerical cracking processes and experimental ones, it is found that the prediction of finite element method is faultlessly consistent with the experimental processes. Both the experimental results and the present numerical results reveal that the crack inclination angle has a great influence on crack coalescence patterns. For increasing inclination angle, the crack coalescence varies from wing crack coalescence to shear crack coalescence. Subsequently, the crack initiation angle $\theta$ is directly measured from the crack trajectory diagrams. Figure 10 summarizes the experimental and numerical value of $\theta$. The figure reveals a positive correlation between $\theta$ and $\beta$, which is consistent with previous studies in $[29,30]$.

Figure 11 shows the failure processes of unequal collinear cracks with varied ligament length $d$. The figure illustrates that wing cracks initiate and propagate first from the inner crack tips at low ligament length value (Figure $11(\mathrm{a}))$. This can be explained with the calculation results shown in Figure 3. It indicates that crack-crack interaction has a stronger effect on inner tips than the one on outer tips when $d<a_{2}$, and for $d>a_{1}$ the mutual effect on crack tips becomes dispensable, which is not sufficient enough to induce a discrepant cracking between inner tips and outer tips. The simulation results also reveal that the crack interaction may change the type of crack coalescence. For bridge ligament less than the length of the short crack $2 a_{2}$, wing and shear cracks have been observed, so that the shear crack coalescence pattern develops afterwards (Figures 11(a) and $11(\mathrm{~b}))$. For $d=2 a_{1}$, a shear crack from the inner tip of the long crack coalesces with a wing crack from the outer tip of the short crack, namely shear-wing crack coalescence. For higher bridge ligament $\left(d>2 a_{1}\right)$, wing cracks first initiate at the tip of the long crack and then the failure occurs because wing cracks develops at the edge of the specimen (Figures 11(d) and 11(e)). In general, the crack coalescence varies from shear crack coalescence to shear-wing crack coalescence and then to the wing crack failure patterns with the increase of bridge ligament.

\section{Conclusions}

(1) The formulation for the SIF of two unequal collinear cracks under compressive stress states is derived through the Kachanov method. The theoretical analysis shows that the short crack has little influence on the propagation of the long crack when the bridge ligament exceeds the short crack length. Moreover, the mutual effects between the two cracks become dispensable when the bridge ligament exceeds the long crack length.

(2) A computing method for the SIF of two winged cracks is introduced. The calculation results show that the SIF first experiences a rush climb and then suffers a rapid drop with the increase of $\beta$. The mutual effect on the SIF of inner tips is stronger than that of outer tips, but this effect diminishes as the wing crack grows.

(3) It is observed experimentally that the crack inclination angle shows a positive correlation of uniaxial compressive strength and crack initiation angle, respectively. It also demonstrates that the crack inclination angle has a significant influence on crack coalescence patterns.

(4) The simulation results indicate that the bridge ligament may change the crack coalescence pattern. For increasing the bridge ligament, the crack coalescence 
varies from shear crack coalescence to shear-wing crack coalescence and then to the wing crack failure patterns.

\section{Conflicts of Interest}

The authors declare that there are no conflicts of interest.

\section{Acknowledgments}

This work was supported by the National Natural Science Foundation of China (nos. 51774131, 51774132, 51374257, and 50804060) and the Project of Geotechnical Engineering Stability Control and Health Monitoring of Hunan Province Key Laboratory, Hunan University of Science and Technology (no. E21619).

\section{References}

[1] H. Qing and W. Yang, "Characterization of strongly interacted multiple cracks in an infinite plate," Theoretical and Applied Fracture Mechanics, vol. 46, no. 3, pp. 209-216, 2006.

[2] S. Q. Yang, X. R. Liu, and H. W. Jing, "Experimental investigation on fracture coalescence behavior of red sandstone containing two unparallel fissures under uniaxial compression," International Journal of Rock Mechanics and Mining Sciences, vol. 63, no. 5, pp. 82-92, 2013.

[3] Y. L. Zhao, L. Y. Zhang, W. J. Wang, C. Pu, W. Wan, and J. Tang, "Cracking and stress-strain behavior of rock-like material containing two flaws under uniaxial compression," Rock Mechanics and Rock Engineering, vol. 49, no. 7, pp. 1-23, 2016.

[4] P. Cao, T. Y. Liu, C. Z. Pu, and H. Lin, "Crack propagation and coalescence of brittle rock-like specimens with pre-existing cracks in compression," Engineering Geology, vol. 187, pp. 113-121, 2015.

[5] Y.Z. Chen, "Multiple crack problems of antiplane elasticity in an infinite body," Engineering Fracture Mechanics, vol. 20, no. 5-6, pp. 767-775, 1984.

[6] Y.Z. Chen, "Numerical solution for multiple crack problem in an infinite plate under compression," International Journal of Fracture, vol. 129, no. 1, pp. 51-62, 2004.

[7] Y. Z. Chen and Z. X. Wang, "Solution of multiple crack problem in a finite plate using coupled integral equations," International Journal of Solids and Structures, vol. 49, no. 1, pp. 87-94, 2012.

[8] M. Kachanov, "Elastic solids with many cracks: a simple method of analysis," International Journal of Solids and Structures, vol. 23, no. 1, pp. 23-43, 1987.

[9] M. Kachanov, "Effective elastic properties of cracked solids: critical review of some basic concepts," Applied Mechanics Reviews, vol. 45, no. 8, pp. 304-335, 1992.

[10] Y. P. Li, L. G. Tham, Y. H. Wang, and Y. Tsui, "A modified Kachanov method for analysis of solids with multiple cracks," Engineering Fracture Mechanics, vol. 70, no. 9, pp. 1115-1129, 2003.

[11] H. Lekesiz, N. Katsube, S. I. Rokhlin, and R. R. Seghi, "The stress intensity factors for a periodic array of interacting coplanar penny-shaped cracks," International Journal of Solids and Structures, vol. 50, no. 1, pp. 186-200, 2013.

[12] G. Kastratović, A. Grbović, and N. Vidanović, "Approximate method for stress intensity factors determination in case of multiple site damage," Applied Mathematical Modelling, vol. 39, no. 19, pp. 6050-6059, 2015.

[13] P. V. Jogdand and K. S. R. K. Murthy, "A finite element based interior collocation method for the computation of stress intensity factors and T-stresses," Engineering Fracture Mechanics, vol. 77, no. 7, pp. 1116-1127, 2010.

[14] M. Basista and D. Gross, "A note on crack interactions under compression," International Journal of Fracture, vol. 102, no. 3, pp. 67-72, 2000.

[15] H. Horii and S. Nemat-Nasser, "Compression-induced microcrack growth in brittle solids: axial splitting and shear failure," Journal of Geophysical Research Solid Earth, vol. 90, pp. 3105-3125, 1985.

[16] F. Lehner and M. Kachanov, "On modelling of "winged" cracks forming under compression," International Journal of Fracture, vol. 77, no. 4, pp. 64-67, 1996.

[17] P. Baud, T. Reuschlé, and P. Charlez, "An improved wing crack model for the deformation and failure of rock in compression," International Journal of Rock Mechanics and Mining Sciences and Geomechanics Abstracts, vol. 33, no. 5, pp. 539-542, 1996.

[18] Y. H. Wang, Y. Xu, L. G. Tham et al., "An improved calculative model for wing crack," Chinese Journal of Geotechnical Engineering, vol. 22, no. 5, pp. 612-615, 2000, in Chinese.

[19] H. Haeri, K. Shahriar, M. F. Marji, and P. Moarefvand, "On the strength and crack propagation process of the pre-cracked rock-like specimens under uniaxial compression," Strength of Materials, vol. 46, no. 1, pp. 140-152, 2014.

[20] C. H. Park and A. Bobet, "Crack initiation, propagation and coalescence from frictional flaws in uniaxial compression," Engineering Fracture Mechanics, vol. 77, no. 14, pp. 27272748, 2010.

[21] H. Lee and S. Jeon, "An experimental and numerical study of fracture coalescence in pre-cracked specimens under uniaxial compression," International Journal of Solids and Structures, vol. 48, no. 6, pp. 979-999, 2011.

[22] L. N. Y. Wong and H. H. Einstein, "Crack coalescence in molded gypsum and carrara marble: part 1. Macroscopic observations and interpretation," Rock Mechanics and Rock Engineering, vol. 42, no. 3, pp. 475-511, 2009.

[23] J. T. Tan and B. K. Chen, "A new method for modelling the coalescence and growth of two coplanar short cracks of varying lengths in AA7050-T7451 aluminium alloy," International Journal of Fatigue, vol. 49, no. 2, pp. 73-80, 2013.

[24] A. Kotousov and D. Chang, "Theoretical and experimental study of fatigue growth of interacting cracks," International Journal of Fatigue, vol. 70, pp. 130-136, 2015.

[25] J. Xi, Z. Chen, and W. Zhang, "Fracture mechanics analysis of unequal cracks interaction under uniaxial tension," Chinese Journal of Rock Mechanics and Engineering, vol. 33, pp. 3625-3630, 2014, in Chinese.

[26] Y. Zhao, C. L. Wang, and W. Wan, "Seepage flow during crack propagation process and stress coupled model under compression-shear stress conditions," Rock and Soil Mechanics, vol. 37, no. 8, pp. 2180-2186, 2016, in Chinese.

[27] T. F. Wong, R. H. C. Wong, K. T. Chau, and C. A. Tang, "Microcrack statistics, Weibull distribution and micromechanical modeling of compressive failure in rock," $\mathrm{Me}$ chanics of Materials, vol. 38, no. 7, pp. 664-681, 2006.

[28] Y. P. Li, L. Z. Chen, and Y. H. Wang, "Experimental research on pre-cracked marble under compression," International Journal of Solids and Structures, vol. 42, no. 9-10, pp. 25052516, 2005. 
[29] H. Q. Li and L. N. Y. Wong, "Influence of flaw inclination angle and loading condition on crack initiation and propagation," International Journal of Solids and Structures, vol. 49, no. 18, pp. 2482-2499, 2012.

[30] X. P. Zhang and L. N. Y. Wong, "Cracking processes in rocklike material containing a single flaw under uniaxial compression: a numerical study based on parallel bonded-particle model approach," Rock Mechanics and Rock Engineering, vol. 45, no. 5, pp. 711-737, 2012. 


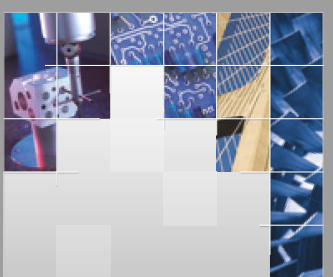

\section{Enfincering}
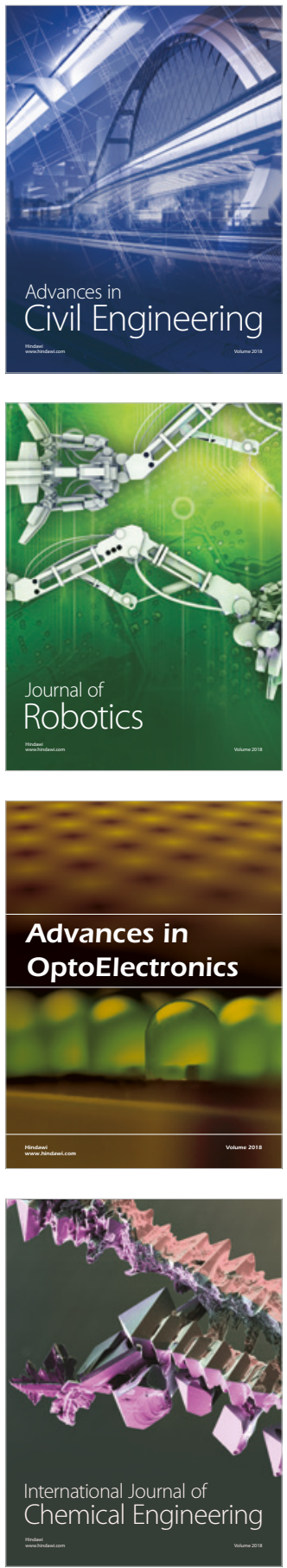

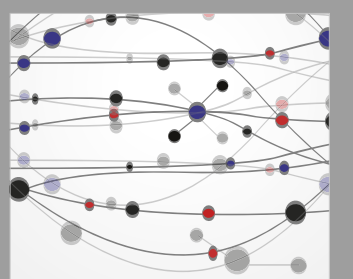

\section{Rotating \\ Machinery}

The Scientific World Journal

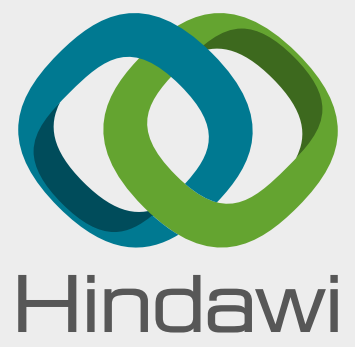

Submit your manuscripts at

www.hindawi.com
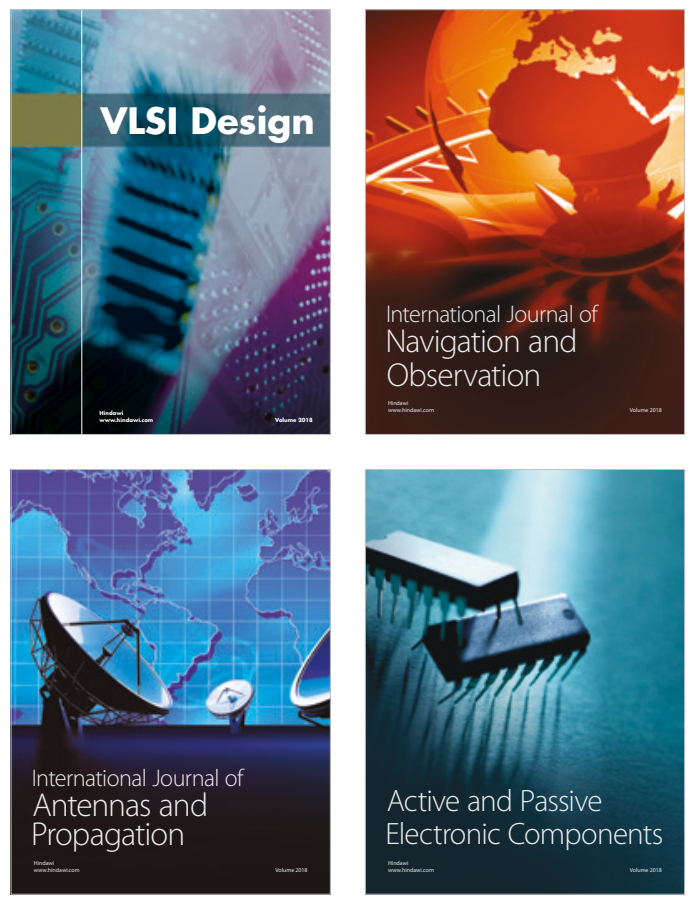
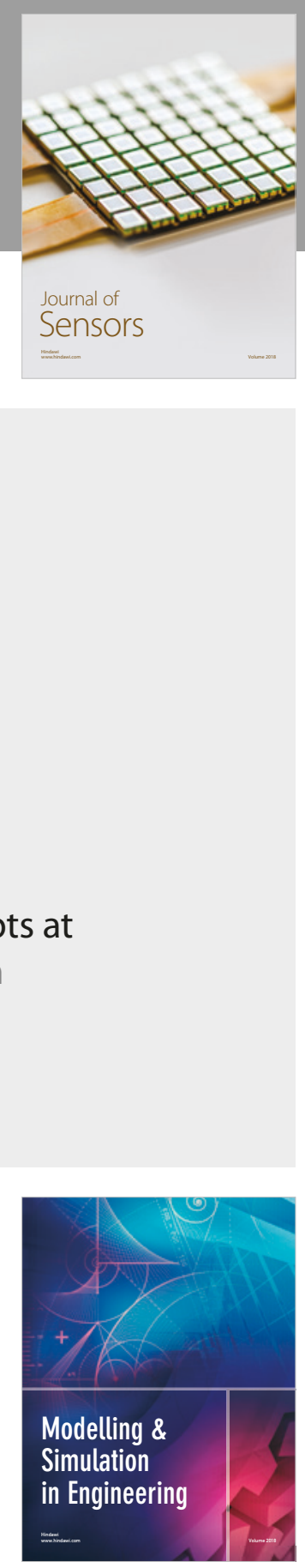

\section{Advances \\ Multimedia}
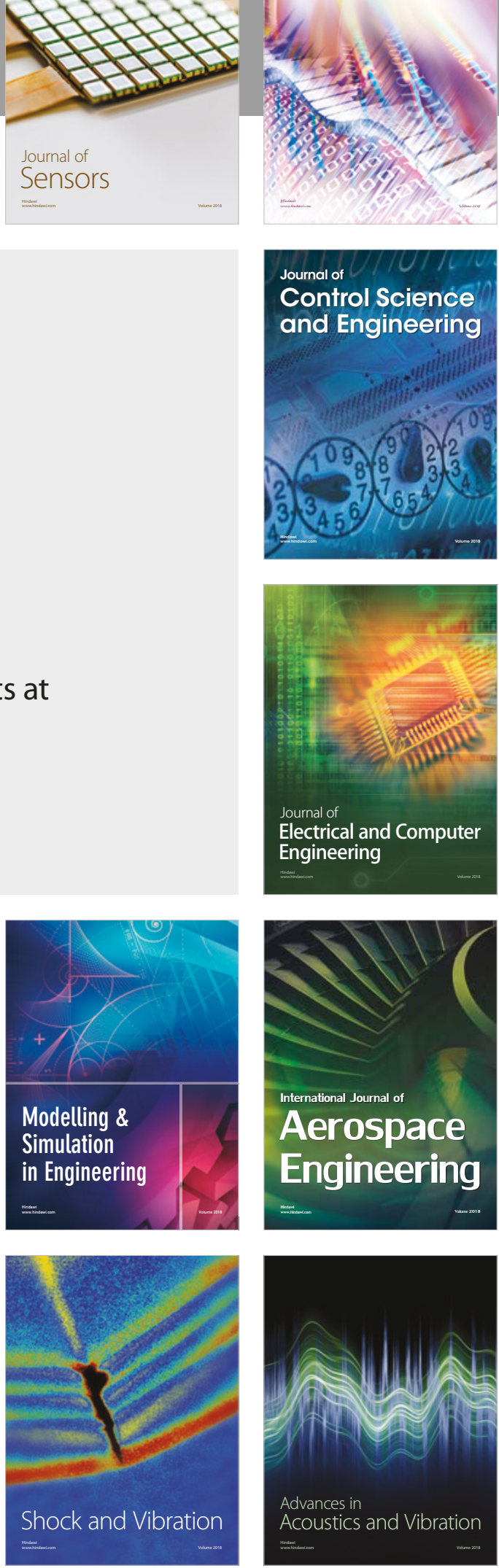